Marquette University

e-Publications@Marquette

Nursing Faculty Research and Publications

Nursing, College of

5-1-2010

Nurse and Patient Perceptions of Discharge Readiness in Relation to Postdischarge Utilization

Marianne E. Weiss

Marquette University, marianne.weiss@marquette.edu

Olga Yakusheva

Marquette University, olga.yakusheva@marquette.edu

Kathleen L. Bobay

Marquette University, kbobay@luc.edu

Accepted version. Medical Care, Vol. 48, No. 5 (May 2010): 482-486. DOI. (C) 2010 Lippincott Williams \& Wilkins, Inc. Used with permission.

This article was originally published by Lippincott, Williams \& Wilkins. For more information about accessing the definitive published version of this article, consult the journal's website at:

http://journals.lww.com/lww-medicalcare/pages/default.aspx 


\section{Nurse and Patient Perceptions of Discharge Readiness in Relation to Postdischarge Utilization}

Authors: Marianne Weiss, RN, DNSc, Olga Yakusheva, PhD, and Kathleen Bobay, RN, PhD

Abstract: Background: Prevention of hospital readmission and emergency department (ED) utilization will be a crucial strategy in reducing health care costs. There has been limited research on nurse assessment and patient perceptions of discharge readiness in relation to postdischarge outcomes.

Objectives: To investigate the association of nurse and patient assessments of discharge readiness with postdischarge readmissions and ED visits.

Research Design: Hierarchical regression analysis of readmission or ED utilization using independent nurse and patient assessments of discharge readiness and patient characteristics as explanatory variables, with hospital and unit fixed effects.

Subjects: A total of 162 adult medical-surgical patients and their discharging nurses from 13 medical-surgical units of 4 Midwestern hospitals.

Measures: Readiness for Hospital Discharge Scale completed independently by patients and their discharging nurses within 4 hours before hospital discharge; Postdischarge utilization (unplanned readmission or ED visit within 30 days postdischarge).

Results: Correlations between nurse assessment and patient perceptions of discharge readiness were low $(r=0.15-0.32)$. Nurses rated patient readiness higher than patients themselves. Controlling for patient characteristics, nurse readiness for hospital discharge scale score (odds ratio $=0.57, P=0.05$ ) but not patient readiness for hospital discharge scale score was associated with postdischarge utilization.

Conclusions: Nurse assessment was more strongly associated with postdischarge utilization than patient self-assessment. Formalizing nurse assessment of discharge readiness could facilitate identification of patients at risk for readmission or ED utilization before discharge when anticipatory interventions could prevent avoidable postdischarge utilization.

Hospital discharge and the transition home are critical processes in the trajectory of acute care. Readmission and emergency department (ED) utilization within 30 days following hospitalization represent unplanned, adverse, potentially avoidable, and .costly outcomes of hospitalization that may be attributed in part to inadequate predischarge, preparation, lack of

1 Weiss, Yakusheva \& Bobay 
patient and family readiness, poor discharge transition coordination, and unsuccessful coping with the demands of self-management at home. ${ }^{1-6}$

More than 34 million patients are discharged annually, ${ }^{7}$ and nurses have a primary role in preparing patients for discharge. Patients and their care team have different perspectives about readiness for hospital discharge. ${ }^{8,9}$ Patients' perceptions have received limited attention in studies of discharge and postdischarge outcomes, with discharge readiness typically measured using single-item questions with dichotomous or ordinal responses. ${ }^{10}$ Discharge readiness is also inferred through proxy measures such as feeling prepared, knowledge, or the occurrence of postdischarge difficulties with activities of daily living, medication and pain management, health maintenance, emotional adjustment, burden to family caregivers, and access to health and social services. ${ }^{2,11-13}$ Discharge programs recommend care management practices that facilitate successful discharge transitions. ${ }^{2,14-16}$ Although incorporating extensive program components and cost-quality outcomes, these programs asses discharge readiness as patient self-perception of preparedness, ${ }^{2}$ and quality of the discharge transition, ${ }^{17,18}$ measured days or weeks after discharge. Measured prior to discharge with the Readiness for Hospital Discharge Scale (RHDS) adult medical-surgical patients' perceptions of their discharge readiness were associated with postdischarge coping and readmission. ${ }^{19}$ The purpose of this study was to investigate the relationships between nurse $(\mathrm{RN})$ and patient assessments of readiness for hospital discharge measured using the $\mathrm{RHDS}^{10}$ and their association with readmission and ED visits during the 30 days following discharge.

\section{Methods}

Data were drawn from a larger study of the sequential relationships of nurse staffing, quality of discharge teaching, readiness of hospital discharge, and posthospitalization readmission, and ED utilization. The parent study sample consisted of 1892 adult inpatients, selected using a within-nursing unit random selection process from 16 medical-surgical units within 4 hospitals ( 2 teaching and 2 community hospitals of 197 to 730 beds) of a not-for-profit magnet-designated Midwestern health care system. Inclusion criteria were at least 18 years of age, spoke and read English or Spanish, and discharged directly home. Home hospice patients were excluded.

A convenience sample of nurses who were assigned to provide care to already enrolled patients on the day of discharge was recruited in the later stages of the parent study. The final sample for this study consisted of 162 nurse-patient pairs for whom nurse and patient discharge

2 Weiss, Yakusheva \& Bobay 
readiness assessments were completed. Nurses may have completed more than one patient assessment. Analysis of nurse characteristics collected for description of the sample (experience, education, expertise) revealed that 132 of the 162 assessments had unique sets of nurse characteristics.

Patient characteristics obtained from electronic information systems included APR-DRG-based coding data: age, sex, major diagnostic category, type of admission (medical or surgical), severity of illness, mortality risk, and length of hospital stay. Socioeconomic status (calculated using the Hollingshead Four Factor Index of Social Status, ${ }^{20}$ which incorporates education and occupation of individuals and spouses as appropriate to generate a score of 8 to 66) and living arrangement (living alone) were obtained from an enrollment questionnaire.

\section{Measures}

\section{Readiness for Hospital Discharge Scale}

The RHDS ${ }^{9}$ was developed to assess patients' perceptions of readiness for discharge and has been tested with adult medical-surgical and other patient populations. ${ }^{19,21,22}$ The 21 -item summated rating scale includes 4 subscales: (1) Personal Status-how the patient is feeling on the day of discharge; (2) Knowledge-how much the patient knows about discharge information related to self-management at home (for example, medications, medical treatments, restrictions, and access to care provider); (3) Perceived coping ability-how well the patient will be able to manage care demands at home; and (4) Expected support-how much help and emotional support will be available. Patients respond on a scale from 0 to 10 with higher ratings indicating greater perceived readiness.

In previous testing with 121 adult medical-surgical patients, the Cronbach's alpha reliability coefficient was 0.93 for the total scale and 0.82 to 0.90 for the subscales. ${ }^{10}$ Reliability estimates for this sample are presented in Table 1. Confirmatory factor analysis with this study's parent sample added to previously reported results that supported the scale's construct validity. ${ }^{10}$

For this study, wording of the RHDS was modified to create a nurse version (hereafter referred to as RNRHDS) on which the discharging nurse was asked to rate patient readiness using the same scale items and response format. For example, the RHDS item "How would you describe your strength today?" was reworded in the nurse version to read "How would you describe your patient's strength today?" All scale items were similarly reworded.

\section{Postdischarge Utilization}

The outcome variable was unplanned readmission or ED visit within 30 days after hospital discharge. Both types of occurrences reflect the need for additional services to manage 
actual or perceived adverse events in the immediate postdischarge period. Because of the small sample size, occurrences were pooled to create a single dichotomous variable representing any unplanned occurrence of readmission or ED use. Electronic searches of patient records across the 4 study hospitals permitted inclusion of readmission/ED occurrences to any facility. Medical records were reviewed by 2 of the investigators to verify the occurrences as unplanned. The readmission/ED visit rate was $16.7 \%$ (27 occurrences: 17 readmissions, 10 ED visits without readmission).

\section{Procedures}

After university and study site IRB approvals, informed consent was obtained from patient participants. With IRB approval for waiver of written documentation of consent, nurses were provided with a written and verbal description of the study and invited to participate. Patients and nurses were asked to complete the RHDS and RNRHDS independently within 4 hours before discharge. Nurse and patient data were linked by patient code number; nurse identifiers were not recorded.

\section{Data Analysis Methods}

Descriptive statistics were calculated for all variables. Paired $t$ tests were used to compare RHDS and RNRHDS scores. Three logistic regression equations were used to examine the relationships of RHDS, RNRHDS, and the combined contributions of RHDS and RNRHDS to the likelihood of postdischarge utilization, controlling for patient characteristics. We included unit and hospital-level fixed effects in all models to control for unit and hospital-level factors not otherwise accounted for in the models. The log-likelihood test of the hierarchical structure of the data rejected clustering at the nurse level $(P=0.23)$ and confirmed clustering at the unit level $(P$ $=0.00)$. Significant unit-level intraclass correlations were detected for type of admission (0.38, $95 \% \mathrm{Cl}=0.18-0.58)$, mortality risk $(0.22,95 \% \mathrm{Cl}=0.06-0.37)$, and length of stay $(0.12,95 \% \mathrm{Cl}=$ 0.00-0.23), and were expected due to patient assignment to specialty focused nursing units. No significant intraclass correlations at the hospital level were detected. To correct for unit-level clustering, we used Huber-White robust standard errors in all models. ${ }^{23}$ For continuous independent variables, polynomial terms were tested and included if significant.

\section{Results}

Descriptors of the patient and nurse samples are included in Table 2. None of the sample characteristics were statistically different from the parent sample. Mean patient and nurse ratings on the RHDS and RNRHDS total scale and subscales ranged from 7.5 to 8.9 out of 10 . Nurses 
reported significantly greater patient readiness than patients themselves on the total scale and personal status and knowledge subscales (Table 1).

The estimation results for the regression analyses of readmission/ED visit on RHDS (Model 1), RNRHDS (Model 2), and both RHDS and RNRHDS (Model 3) with patient characteristics included in the models are reported in Table 3. RHDS in Model 1 was not statistically significant $(B=-0.25, P=0.19$, odds ratio $=0.78)$. In Model 2, RNRHDS had a significant inverse relationship with postdischarge utilization $(B=-0.60, P=0.02$, odds ratio $=$ 0.55). When both RHDS and RNRHDS were included in Model 3, RNRHDS remained inversely associated with postdischarge utilization while the independent effect of RHDS remained insignificant (RHDS: $\mathrm{B}=-0.17, P=0.42$, odds ratio $=.84$; RNRHDS: $\mathrm{B}=-0.56, P=0.049$, odds ratio $=0.57$ ). In all models for postdischarge utilization, age, and medical type admission were statistically significant.

\section{Discussion}

The primary finding of the study is that nurse assessment of discharge readiness was more strongly associated with postdischarge utilization than patient self-assessment. Nurses reported greater levels of patient readiness than patients themselves, particularly in the areas of personal status and knowledge. In a previous comparison of nurse and patient perceptions, nurses underestimated postdischarge functional ability and overestimated knowledge of the postdischarge plan. ${ }^{9}$

Nurse assessment of discharge readiness (RNRHDS) significantly augmented patient characteristics in explaining the likelihood of postdischarge utilization, and consistent with previous reports, age, and medical-type admission were associated with postdischarge utilization. ${ }^{3,24,25}$ Adding discharge readiness assessment to models for predicting early readmission risk ${ }^{26}$ and preventable hospitalizations ${ }^{24}$ could improve their usefulness for predischarge identification of high-risk patients. Formalized assessment of discharge readiness, with specific triggers for anticipatory interventions before discharge or for postdischarge continued care or surveillance, could improve patient outcomes and satisfaction at the time of discharge and reduce unintended and costly adverse outcomes and health service utilization postdischarge. Interventions might include additional patient or family teaching, case management, community referral, additional in-hospital surveillance, or referral to discharge transition programs and services.

Although patient perceptions of their discharge readiness were not associated with 
readmission/ED use in this study sample, they represent an expression of patients' immediate reality and are important from a patient-centered care perspective whether their postdischarge condition rises to a threshold sufficient to trigger reaccessing health care services. The quality of patients' postdischarge experiences including difficulties with coping at home and burden to family have been reported in other studies ${ }^{4,6,13,19,27,28}$ and were not assessed in this study. An association between patient perception of discharge readiness and postdischarge coping difficulty has also been previously reported. ${ }^{19}$

Limitations include small sample size and convenience sampling of nurses within a 4 hospital magnet-designated health care system. These limitations preclude generalization of findings to broad patient and nurse populations and to other healthcare settings without further study. With inclusion of adult patients from 18 years of age and slightly more surgical than medical patients, the results are not directly comparable to studies that have focused on elderly patients and specific diagnostic groups. The wide range of medical conditions, represented by major diagnostic category, type of admission, severity of illness, and mortality risk variables, is a strength in terms of broad applicability of the RNRHDS, and a limitation in terms of unmeasured clinical parameters that may influence study results. Nurse assessment of discharge readiness was conducted using an instrument designed for patient self-assessment. Further development and testing of the RNRHDS are needed to determine if the attributes of discharge readiness are the same for patients and their nurses. Additions or refinements in the attribute structure of the nurse version of the scale may be needed as further development and validity testing proceed.

Screening for readmission or ED visits occurred across the 4 study hospitals but utilization records at other facilities including 19 hospitals in the Metropolitan Statistical Area ${ }^{29}$ were not accessible. Follow-up telephone calls to a random sample of parent study enrollees revealed one readmission and one ED visit to non study facilities (1.4\% of the follow-up sample, none of which occurred in this study sample). Links to vital records to identify postdischarge deaths were not attempted. Under-detection of postdischarge utilization could affect the study results and should be corrected in future larger studies. Readmissions and ED visits were combined as postdischarge occurrences. In future larger studies, different relationships of discharge readiness with readmission and ED utilization could be detected.

\section{Conclusions}

The results of this study provide preliminary evidence of association between nurse assessment of discharge readiness and likelihood of postdischarge utilization. Discharge 
readiness assessment could be a useful tool for early identification of patients who are at risk for readmission or ED utilization during the immediate posthospitalization period. Further testing of nurse assessment of discharge readiness, coupled with anticipatory interventions and targeted follow-up, is needed to support national efforts to reduce hospital readmissions and ED utilization.

\section{Notes}

- From the Marquette University College of Nursing and College of Business Administration, Department of Economics, Milwaukee, WI.

- Supported by Robert Wood Johnson Foundation Interdisciplinary Nursing Quality Research Initiative.

- Reprints: Marianne Weiss, RN, DNSc, Marquette University College of Nursing, PO Box 1881, Milwaukee, WI 53201. E-mail: Marianne.weiss@ marquette.edu.

\section{References}

1. Friedman B, Basu J. The rate and cost of hospital readmissions for preventable conditions. Med Care Res Rev. 2004;61:225-240.

2. Jack BW, Chetty $Y K$, Anthony $D$, et al. Reengineered hospital discharge program to decrease rehospitalization: a randomized trial. Ann Intern Med.2009;150:178-187.

3. Minott J. Reducing Hospital Readmissions. Washington, DC: Academy Health. 2008. Available at: http://www.academyhealth.org/files/publications/Reducing_Hospital. Accessed April 8, 2009.

4. Mistiaen P, Francke AL, Poot E. Interventions aimed at reducing problems in adult patients discharged from hospital to home: a systematic meta-review. BMC Health Serv Res. 2007;7:47-65.

5. Vinson JM, Rich MW, Sperry JC, et al. Early readmission of elderly patients with congestive heart failure. J Am Geriatr Soc. 1990;38:1290-1295.

6. Mamon J, Steinwachs DM, Fahey M, et al. Impact of hospital discharge planning on meeting planning needs after returning home. Health Serv Res. 1992;27:155-175.

7. DeFrances CJ, Lucas CA, Buie VC, et al. 2006 National Hospital Discharge Survey. National health statistics reports; no 5. Hyattsville, MD: National Center for Health Statistics; 2008.

8. Congdon JG. Managing the incongruities: the hospital discharge experience for elderly patient, their families, and nurses. Appl Nurs Res. 1994;7:125-131.

7 Weiss, Yakusheva \& Bobay 
9. Reiley P, lezzoni LI, Phillips R, et al. Discharge planning: comparison of patients' and nurses' perceptions of patients following hospital discharge. Image J Nurs Sch. 1996;28:143-147.

10. Weiss ME, Piacentine LB. Psychometric properties of the readiness for hospital discharge scale. J Nurs Meas. 2006;14:163-180.

11. Bull MJ, Hansen HE, Gross CR. Predictors of elder and family caregiver satisfaction with discharge planning. J Cardiovasc Nurs. 2000;14:76-87.

12. Clark M, Steinberg M, Bischoff N. Patient readiness for return to home: discord between expectations and reality. Aust Occup Ther J. 1997;44:132-141.

13. LeClerc CM, Wells $D$, Craig $D$, et al. Falling short of the mark: tales of life after hospital discharge. Clin Nurs Res. 2002;11:242-263.

14. Coleman EA, Parry C, Chalmers $S$, et al. The care transitions intervention: results of a randomized controlled trial. Arch Intern Med. 2006;166:1822-1828.

15. Naylor MD, Brooten D, Campbell R, et al. Comprehensive discharge planning and home follow-up of hospitalized elders: a randomized clinical trial. JAMA. 1999;281:613-620.

16. Nielsen GA, Bartely A, Coleman E, et al. Transforming Care at the Bedside How-to Guide: Creating an Ideal Transition Home for Patients with Heart Failure. Cambridge, MA: Institute for Healthcare Improvement; 2008. Available at: http://www.ihi.org.

17. Coleman EA, Mahoney E, Parry C. Assessing the quality of preparation for posthospital care from the patient's perspective: the care transitions measure. Med Care. 2005;43:246-255.

18. Parry C, Mahoney E, Chalmers SA, et al. Assessing the quality of transitional care: further applications of the care transition measure Med Care. 2008;46:317-322.

19. Weiss $M$, Piacentine L, Lokken L, et al. Perceived readiness for hospital discharge in adult medical-surgical patients. Clin Nurs Spec. 2007;21:31-42.

20. Hollingshead A. Four Factor Index of Social Status (Working Paper). New Haven, CT: Hollingshead; 1975.

21. Weiss M, Johnson N, Malin S, et al. Predictors and outcomes of readiness for hospital discharge in parents of hospitalized children. J Pediatr Nurs. 2008;23:282-295.

22. Weiss ME, Lokken L. Predictors and outcomes of readiness for discharge after birth. J Obstet Gynecol Neonatal Nurs. 2009;38:406-417.

23. Huber P. Robust Statistics. New York, NY: Wiley and Sons; 1974.

24. Goldfield NI, Elizabeth MD, McCullough C, et al. Identifying potentially preventable readmissions. Health Care Financ Rev. 2008;30:75-91.

25. Anderson MA, Levsen J, Dusio ME, et al. Evidence-based factors in readmission of patients

8 Weiss, Yakusheva \& Bobay 
with heart failure. J Nurs Care Qual. 2006;21:160-167.

26. Novotny NL, Anderson MA. Prediction of early readmission in medical inpatients using the probability of repeated admission instrument. Nurs Res. 2008;57:406-415.

27. Miller JM, Piacentine LB, Weiss M. Coping difficulties after hospitalization. Clin Nurs Res. 2008;17:278-296.

28. Bull MJ, Jervis LL. Strategies used by chronically ill older women and their care giving daughters in managing posthospital care. J Adv Nun. 1997;25:541-547.

29. American Hospital Association. AHA Hospital Statistics. Chicago, IL: Health Forum; 2009.

30. Haag-Heitman B. Clinical Practice Development Using Novice to Expert Theory. Gaithersburg, MD: Aspen Publishers; 1999.

\section{Appendix}

\section{Table 1}

\section{RHDS and RNRHDS Scale Statistics}

\begin{tabular}{|c|c|c|c|c|c|}
\hline \multirow{2}{*}{$\begin{array}{l}\text { Readiness for Hospital } \\
\text { Discharge Scale } \\
\text { Total scale: Item mean (SD) }\end{array}$} & \multirow{2}{*}{$\begin{array}{c}\begin{array}{c}\text { Patient [RHDS] } \\
\text { Mean (SD) }\end{array} \\
8.1(1.3)\end{array}$} & \multirow{2}{*}{$\begin{array}{c}\begin{array}{c}\text { Nurse [RNRHDS] } \\
\text { Mean (SD) }\end{array} \\
8.6(1.0)\end{array}$} & \multirow{2}{*}{$\begin{array}{c}\begin{array}{c}\text { Paired } \boldsymbol{t} \text { Test RHDS } \\
\text { \& RNRHDS }\end{array} \\
t(161)=-4.09, P=0.00\end{array}$} & \multicolumn{2}{|c|}{$\begin{array}{l}\text { Cronbach Alpha } \\
\text { RHDS RNRHDS }\end{array}$} \\
\hline & & & & 0.87 & 0.90 \\
\hline \multicolumn{6}{|l|}{ Subscales } \\
\hline Personal status & $7.5(1.5)$ & $8.3(1.1)$ & $t(159)=-6.52, P=0.00$ & 0.69 & 0.75 \\
\hline Knowledge & $8.3(1.5)$ & $8.9(1.1)$ & $t(157)=-4.56, P=0.00$ & 0.84 & 0.92 \\
\hline Perceived coping ability & $8.7(1.6)$ & $8.7(1.3)$ & $t(161)=-0.12, P=0.91$ & 0.84 & 0.89 \\
\hline Expected support & $8.1(2.6)$ & $8.2(2.1)$ & $t(158)=-0.54, P=0.59$ & 0.88 & 0.88 \\
\hline
\end{tabular}

RHDS: Readiness for Hospital Discharge Scale, patient version; RNRHDS, Readiness for Hospital Discharge Scale, nurse version. 


\section{Table 2}

Characteristic of the Study Sample $(\mathrm{N}=162)$

\begin{tabular}{|c|c|c|}
\hline Characteristic & Patient & Nurse \\
\hline Age: mean (SD) & 58.7 (17.1) (range, 19-94) & \\
\hline Sex: male N (\%) & $78(48.1)$ & \\
\hline $\begin{array}{c}\text { Socioeconomic status: } \\
\text { mean (SD) }\end{array}$ & $38.3(13.5)$ & \\
\hline Lives alone: N (\%) & $37(22.8)$ & \\
\hline \multicolumn{2}{|l|}{ Type of diagnosis } & \\
\hline Medical N (\%) & $79(48.8)$ & \\
\hline Surgical N (\%) & $83(51.2)$ & \\
\hline \multicolumn{2}{|l|}{ Major diagnostic category } & \\
\hline MDC 1: Nervous system & $20(12.3)$ & n \\
\hline $\begin{array}{l}\text { MDC 4: Respiratory } \\
\text { system }\end{array}$ & $13(8.0)$ & \\
\hline $\begin{array}{l}\text { MDC 5: Circulatory } \\
\text { system }\end{array}$ & $44(27.2)$ & \\
\hline MDC 6: Digestive system & $14(8.6)$ & \\
\hline $\begin{array}{l}\text { MDC 7: Hepatobiliary/ } \\
\text { pancreas }\end{array}$ & $7(4.3)$ & \\
\hline MDC 8: Musculoskeletal & $45(27.8)$ & \\
\hline $\begin{array}{l}\text { MDC 11: Kidney/urinary } \\
\text { tract }\end{array}$ & $8(4.9)$ & \\
\hline MDC - other & $11(6.8)$ & \\
\hline \multicolumn{2}{|l|}{ Severity of illness: N (\%) } & \\
\hline 1 & $44(27.2)$ & \\
\hline 2 & $74(45.7)$ & \\
\hline 3 & $40(24.7)$ & \\
\hline 4 & $4(2.5)$ & \\
\hline \multicolumn{3}{|l|}{ Mortality risk: N (\%) } \\
\hline 1 & $99(61.1)$ & \\
\hline 2 & $37(22.8)$ & \\
\hline 3 & $23(14.2)$ & \\
\hline 4 & $3(1.9)$ & \\
\hline Length of stay: mean (SD) & $3.9(3.8)$ & \\
\hline \multicolumn{3}{|l|}{ Postdischarge utilization } \\
\hline Total N (\%) & $27(16.7)$ & \\
\hline Readmission & $17(10.5)$ & \\
\hline ED visit & $10(6.2)$ & \\
\hline $\begin{array}{l}\text { Nurse years of experience: } \\
\text { mean (SD) }\end{array}$ & & $7.3(9.4)$ \\
\hline \multicolumn{3}{|l|}{ Nurse education: N (\%) } \\
\hline Diploma/associate degree & & $56(34.6)$ \\
\hline Bachelor's degree & & $98(60.5)$ \\
\hline Graduate degree & & $5(3.1)$ \\
\hline Missing & & $3(1.9)$ \\
\hline \multicolumn{3}{|l|}{ Nurse expertise ${ }^{30}: \mathrm{N}(\%)$} \\
\hline Not yet classified & & $30(18.5)$ \\
\hline Competent & & $65(40.1)$ \\
\hline Accomplished & & $16(9.9)$ \\
\hline Proficient & & $23(14.2)$ \\
\hline Expert & & $22(13.6)$ \\
\hline Missing & & $6(3.7)$ \\
\hline
\end{tabular}

10 Weiss, Yakusheva \& Bobay 


\section{Table 3}

Odds Ratios (and 95\% Confidence Intervals) From Logistic Regression Analyses of the Relationship Between the Likelihood of Unplanned Readmission or ED Utilization and Patient's and RN's Perceptions of Readiness for Discharge ( $\mathrm{N}=162)$

\begin{tabular}{|c|c|c|}
\hline Characteristic & Odds & Ratio $(95 \% \mathrm{CI})$ \\
\hline \multicolumn{3}{|l|}{ Model 1} \\
\hline Patient-RHDS & 0.78 & $(0.54-1.13)$ \\
\hline Patient age & 2.85 & $(1.42-5.71)^{*}$ \\
\hline Patient is male & 1.33 & $(0.36-4.86)$ \\
\hline Patient lives alone & 1.03 & $(0.15-7.02)$ \\
\hline Family socioeconomic status & 0.99 & $(0.94-1.04)$ \\
\hline Severity & 0.77 & $(0.22-2.69)$ \\
\hline Mortality & 1.48 & $(0.35-6.28)$ \\
\hline LOS & 1.15 & $(1.00-1.34)$ \\
\hline Medical patient & 4.22 & $(1.42-12.49)^{*}$ \\
\hline Pseudo $\mathrm{R}^{2}$ & 0.29 & \\
\hline \multicolumn{3}{|l|}{ Model 2} \\
\hline Nurse-RNRHDS & 0.55 & $(0.33-0.92)^{\dagger}$ \\
\hline Patient age & 3.04 & $(1.22-7.57)^{\dagger}$ \\
\hline Patient is male & 1.23 & $(0.29-5.27)$ \\
\hline Patient lives alone & 1.14 & $(0.16-8.14)$ \\
\hline Family socioeconomic status & 0.99 & $(0.93-1.06)$ \\
\hline Severity & 0.79 & $(0.21-2.96)$ \\
\hline Mortality & 1.26 & $(0.28-5.75)$ \\
\hline LOS & 1.13 & $(0.91-1.41)$ \\
\hline Medical patient & 4.07 & $(1.33-12.44)^{\dagger}$ \\
\hline Pseudo $\mathrm{R}^{2}$ & 0.31 & \\
\hline Model 3 & & . \\
\hline Patient-RHDS & 0.84 & $(0.55-1.28)$ \\
\hline Nurse-RNRHDS & 0.57 & $(0.33-1.00)^{\dagger}$ \\
\hline Patient age & 3.04 & $(1.31-7.05)^{*}$ \\
\hline Patient is male & 1.33 & $(0.34-5.29)$ \\
\hline Patient lives alone & 1.07 & $(0.15-7.52)$ \\
\hline Family socioeconomic status & 0.99 & $(0.93-1.05)$ \\
\hline Severity & 0.79 & $(0.21-2.92)$ \\
\hline Mortality & 1.24 & $(0.27-5.66)$ \\
\hline LOS & 1.14 & $(0.91-1.41)$ \\
\hline Medical patient & 4.23 & $(1.49-12.02)^{*}$ \\
\hline Pseudo $\mathrm{R}^{2}$ & 0.31 & \\
\hline
\end{tabular}

The errors are corrected for clustering at the unit level. The models include polynomial terms for age (squared and cubed statistically significant in all models), controls for patient MDC, and unit-level and hospital-level fixed effects (not reported in the table).

${ }^{\star} P<0.01,{ }^{\dagger} P<0.05$

\section{Weiss, Yakusheva \& Bobay}

